\section{Optimising aesthetics and facilitating clinical application of free-hand bonding using the 'natural layering concept'}

\author{
D. Dietschi ${ }^{1}$
}

\author{
VERIFIABLE CPD PAPER
}

IN BRIEF

- Modern composite resins fulfil many restorative objectives which could only be attained by ceramics in the past, including satisfactory and long-lasting aesthetics.

- The natural layering concept makes use of only two basic masses which mimic dentin and enamel; the technique is therefore simple and accessible to all general practitioners with proper training.

The use of composites in the smile frame has evolved and gained maturity. However, ceramics remain the preferred aesthetic option for many clinicians because bonding techniques are still considered intricate, sensitive and, to a certain extent, unpredictable. These drawbacks, essentially related to the complexity of many composite systems, can be overcome today by the application of the 'natural layering concept', which makes use of only two basics masses, dentine and enamel, perfectly mimicking natural tooth structure. There are plentiful indications for the use of such a simplified but aesthetically uncompromised treatment modality. Actually, this approach is highly suitable for young and post-orthodontic patients where conservation of tissue is a must and in general for all patients with rather healthy dentitions.

\section{INTRODUCTION}

Composite resins today occupy a paramount position among restorative materials because they offer excellent aesthetic potential and acceptable longevity, with a much lower cost than equivalent ceramic restorations for the treatment of both anterior and posterior teeth. ${ }^{1-4}$ In addition, composite restorations allow for minimally invasive preparations or no preparation at all when assuming the replacement of decayed or missing tissues. This thinking is part of a new concept called 'bio-aesthetics', giving priority to non-restorative or additive procedures such as bleaching, microabrasion, enamel recountouring, direct composite resins, and bonded bridges or implants to replace missing

Senior lecturer, Department of Cariology \& Endodontics, School of Dentistry, University of Geneva, Switzerland/Adjunct Professor, Department of Comprehensive Dentistry, Case Western University, Cleveland, Ohio/Private Practice \&t Education Center - The Geneva Smile Center, Switzerland

Correspondence to: Dr Didier Dietschi, Dept. of Cariology \& Endodontics, School of Dentistry, 19 Rue Barthélémy Menn, 1205 Geneva, Switzerland Email: didier.dietschi@medecine.unige.ch

\section{Refereed Paper}

Accepted 1 January 2008

DOI: $10.1038 /$ bdj.2008.100

${ }^{\circledR}$ British Dental Journal 2008; 204: 181-185 teeth. These many procedures definitely deserve more attention because they tremendously improve practicability, efficiency and predictability. ${ }^{4,5-10}$

The creation of perfect direct restorations has been for long an elusive goal because of the imperfect optical properties of composite resins and also because of perfectible clinical procedures. The attempt to mimic shades and layering techniques developed for ceramic restorations led to complicated applications methods, controllable only by highly skilled practitioners. This has limited for years the number of patients who could benefit from the tremendous advantage of free-hand bonding. The use of the natural tooth as a model and the identification of respective dentine and enamel optical characteristics (tristimulus L*a*b* colour measurements and contrast ratio) has then been a landmark in developing better direct tooth coloured materials. ${ }^{11-13}$

The 'natural layering concept' is a simple and effective approach to creating highly aesthetic direct restorations. Since the concept has become a reference in the field of composite restorations, the aim of this paper is to familiarise the practitioner with features of this new technique and related clinical procedures.

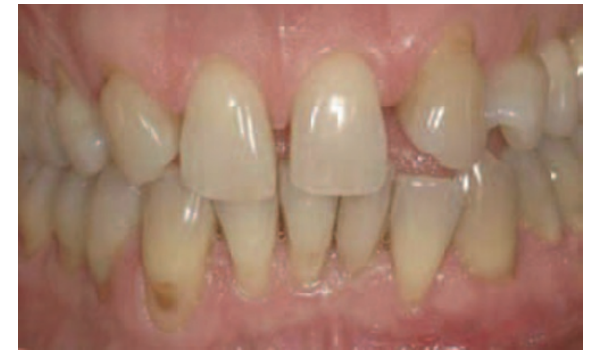

Fig.1a Pre-operative view of a 50-year-old patient with natural arrangement of teeth following bilateral incisor aplasia

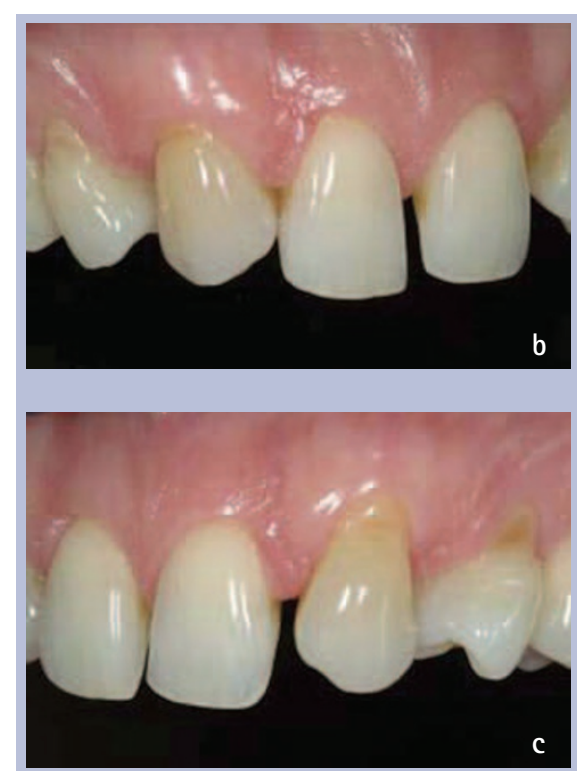

Figs $1 \mathrm{~b}-1 \mathrm{c}$ Lateral views demonstrate the numerous aesthetic deficiencies such as improper space distribution, teeth forms proportions and axis, and abrasion 

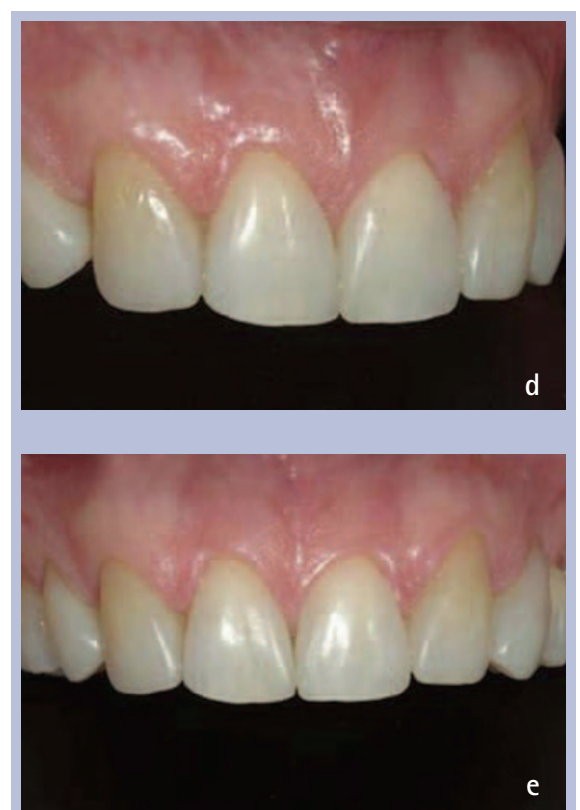

Figs $1 \mathrm{~d}-1 \mathrm{e}$ Post-operative view of reconstructed smile following bleaching and the use of merely additive procedures.

This case illustrates the potential of conservative adhesive dentistry, also in relatively complex cases.

\section{A new array of indications for free-hand bonding}

Besides classical indications such as class III, IV \& $\mathrm{V}$ filling, many other aesthetic or functional problems can be corrected by simple, direct composite restorations (Figs 1-3); these indications are reviewed thereafter.

\section{1) Post-orthodontic conditions}

Lateral incisor aplasia or incorrigible canine impaction are frequent findings often approached by an orthodontic solution, following proper diagnosis of dental and skeletal conditions. ${ }^{15-16}$ However, different anatomical, functional and aesthetic anomalies may result from such orthodontic approach. Other orthodontic conditions (ie tooth size discrepancy [TSD] $)^{17}$ can also lead to the persistence of diastemas or sub-optimal tooth position, following an appropriate treatment. The increasing concern of our patients for aesthetics obliges the dental team to correct these potential deficiencies:

- unusual crown dimensions

- unusual root diameter

- unusual shape of the crown

- difference in colour

- difference in gingival contour or level.

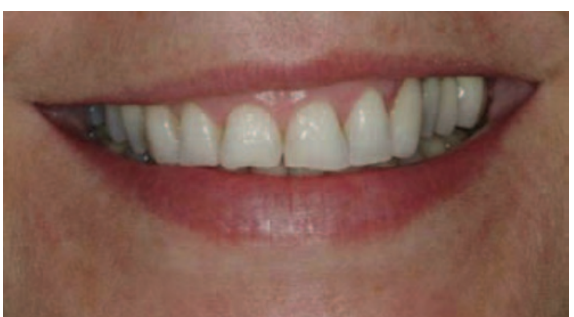

Fig. 2a Typical smile of a 60-year-old patient showing important incisal abrasion and smile ageing

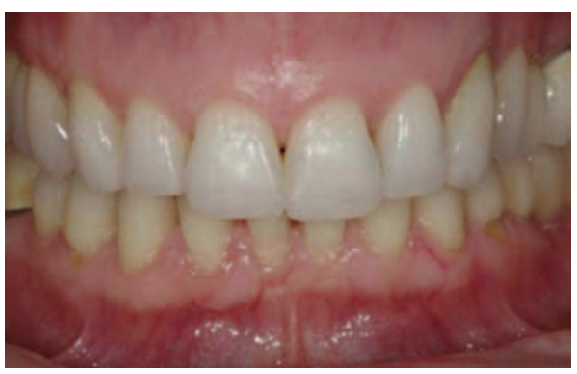

Fig. 2b After lengthening incisal edges of teeth 11 and 21, followed by recountouring of incisal edges in teeth 12 and 22, a younger and more attractive smile line is re-established

\section{2) Congenital aesthetic deficiencies}

Numerous congenital conditions, such as those listed below, require correction at a relatively early stage and therefore mandate a conservative approach:

- displasia/discolourations

- hypoplasia

- unsual tooth forms or dimensions.

\section{3) Acquired and other aesthetic deficiencies}

Many other conditions can develop at different ages which impact smile balance and aesthetics:

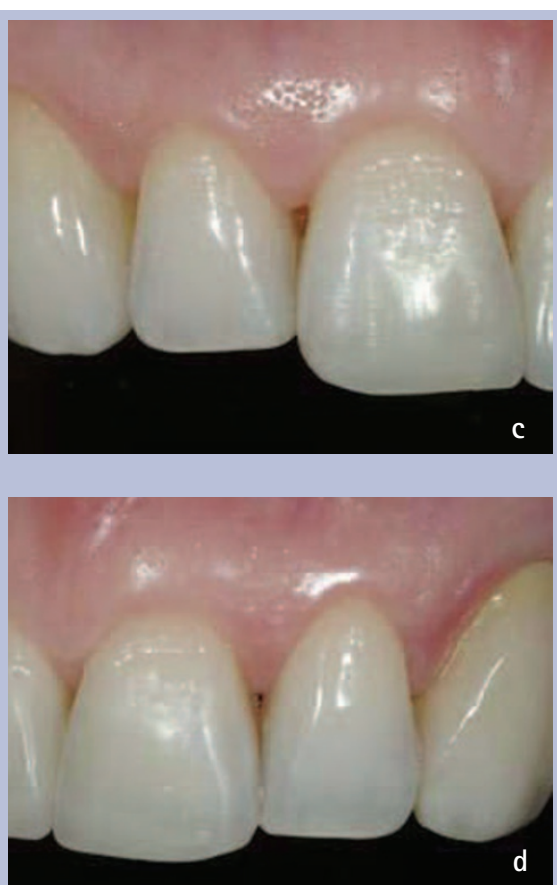

Figs $2 \mathrm{c}-2 \mathrm{~d}$ Detailed views show the rounded angles of teeth 12 and 22 which help to rejuvenate abraded smiles in a very conservative way

- discolourations (ie traumatised non-vital tooth)

- diastemas

- abrasion, abfraction and erosion lesions

- tooth fractures

- caries

- functional deficiencies

Aforementioned conditions are also potential indications for conservative, additive procedures, according to preexisting tissue loss and functional status.

\section{A new shading concept}

The use the natural tooth as a model

Table 1 In vitro CIE L*a*b* (+/- SD) and CR measures of natural teeth of the A \& B VITA shade groups (dentine sections without enamel; average data, $\mathrm{n} 8 /$ shade)

\begin{tabular}{l|l|l|l|l} 
Vita Shade & $\mathrm{L}^{*}$ & $\mathrm{a}^{*}$ & $\mathrm{~b}^{*}$ & $\mathrm{CR}$ \\
\hline A1 & $76.11(3.76)$ & $-3.85(0.49)$ & $11.46(1.56)$ & 0.67 \\
\hline B1 & $77.12(3.76)$ & $-3.23(0.57)$ & $13.08(3.21)$ & 0.63 \\
\hline A2 & $73.88(2.07)$ & $-3.85(0.45)$ & $14.93(2.90)$ & 0.66 \\
\hline B2 & $74.06(3.38)$ & $-3.28(1.0)$ & $13.72(2.81)$ & 0.62 \\
\hline A3 & $74.05(1.96)$ & $-3.82(0.78)$ & $18.11(4.06)$ & 0.67 \\
\hline B3 & $71.52(3.56)$ & $-3.73(0.82)$ & $15.54(3.71)$ & 0.62 \\
\hline A3.5 & $67.67(4.69)$ & $-3.87(0.46)$ & $18.71(3.47)$ & 0.69 \\
\hline A4 & $68.48(3.05)$ & $-2.93(0.92)$ & $19.82(3.35)$ & 0.70
\end{tabular}




\begin{tabular}{|c|c|c|}
\hline Miris ${ }^{\circ}$ Enamel & $\mathrm{L}^{*}$ & CR \\
\hline Young/white & 75.89 & 0.485 \\
\hline Adult/neutral & 66.77 & 0.434 \\
\hline Old/yellow-gray & 71.84 & 0.402 \\
\hline average & 70.83 & 0.435 \\
\hline
\end{tabular}

has been a logical development of direct restorative materials, leading to simplified shading and layering concept, named as the 'natural layering concept'. It is based on the identification of true dentine and enamel optical characteristics using tristimulus $\mathrm{L}^{*} \mathrm{a}^{*} \mathrm{~b}^{*}$ colour (Table 1) and contrast ratio measurements (Table 2). ${ }^{11-13}$

\section{Dentine optical features}

Variations in $\mathrm{a}^{*}$ and $\mathrm{b}^{*}$ dentine values between 'A' and 'B' VITA shades seemed not to justify the use of distinct dentine colours, at least for a direct composite restorative system. ${ }^{13}$ Likewise, the variations of the contrast ratio (opacity-translucency) within a single shade group did not support the use of different dentin opacities (ie translucent, regular or opaque dentines). However, the concept of a large chroma scale covering all variations of natural dentitions, plus some specific conditions like sclerotic dentin (as found underneath decays, fillings or cervical lesions) proved justified.

Therefore, the following recommendations as regard optical characteristics of an ideal material aimed to replace dentin were drawn:

- single hue

- single opacity

- large chroma scale (beyond the four chroma levels of the VITA system).

\section{Enamel characteristics}

As regard enamel, differences in tissue lightness and translucency proved generally to vary in relation with tooth age and therefore confirmed the clinical concept of three specific enamel types:18

- Young enamel: white tint, high opalescence, less translucency

- Adult enamel: neutral tint, less opalescence and intermediary translucency
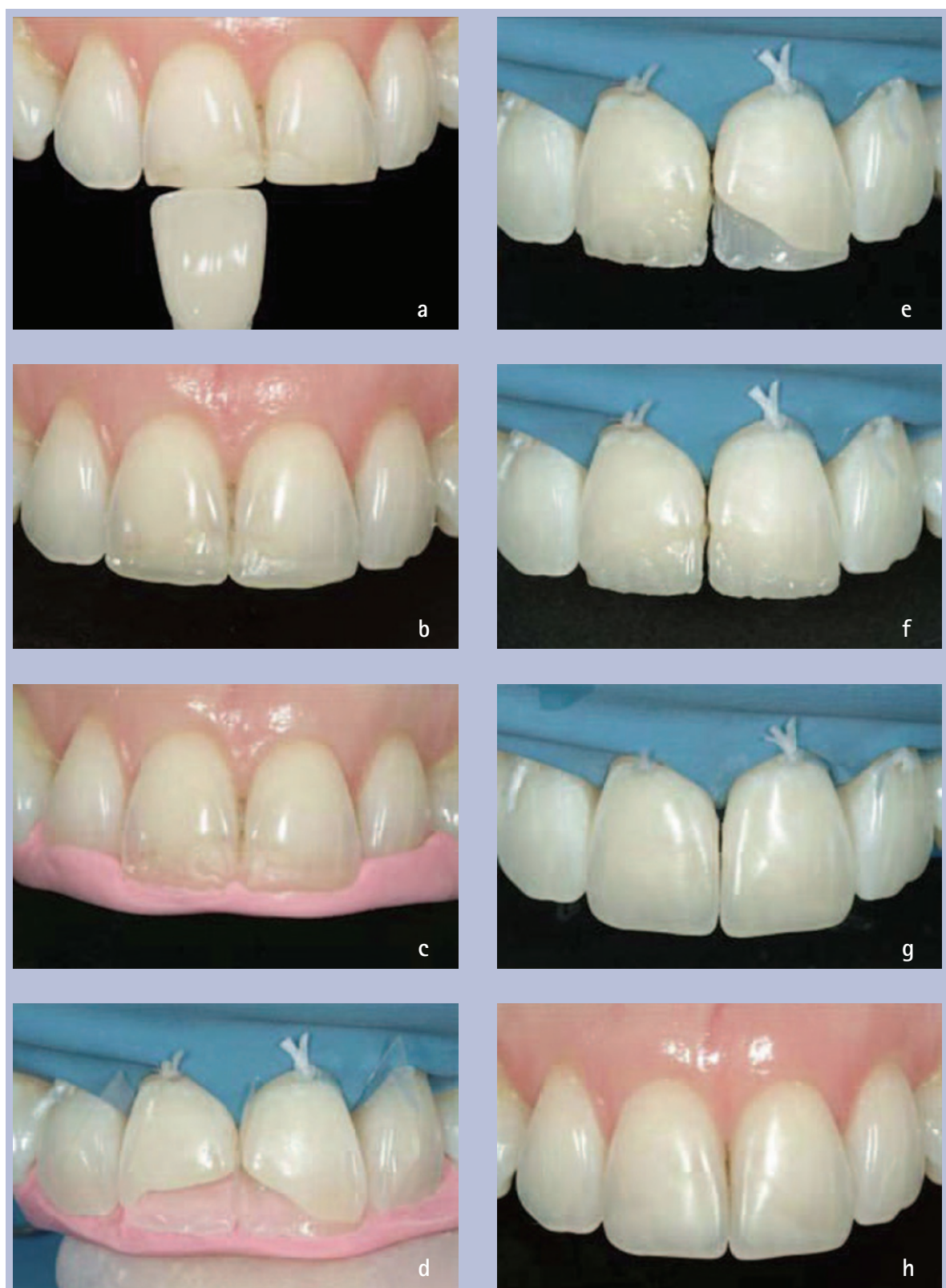

Fig. 3 Build-up of 2 large class IV cavities according to the natural layering concept (a) pre operative view and shade selection with dual MIRIS shade guide; (b) free-hand mock-up which reproduces the normal length and width of the incisal edge; (c) a silicone index fixes this information to facilitate further procedures; (d) the lingual enamels walls are built-up directly against the index; (e) dentine can be applied and placed precisely in relation with future incisal edge, respecting the specific tooth and age configurations; ( $f$ ) effect masses are applied in small quantities on top of dentine to mimic specific light effects such as opalescence (blue tinted); $(g)$ a final enamel layer has been applied on proximal and buccal surfaces to complete the restoration; (h) completed restorations after tissue rehydration

- Old enamel: yellow tint, higher translucency

These findings have logically designed the concept of this new and improved shading concept. Dentines shades are available in one single hue (as average of natural dentine hue) with a sufficient range of chroma levels (covering at least the existing Vita shade range) and presenting opacity similar to natural dentine. Enamel shades should present different tints and opacity levels, tentatively replicating all variations found in nature. Typical brand names are Miris and Miris2 (Coltenewhaledent), Ceram-X duo (Dentsply) or as well Enamel HFO (Micerium).

\section{Clinical application of the natural layering concept}

\section{Shade recording with the natural} layering concept

The quality of the final restoration depends of course on a correct shade 
recording. According to the natural layering concept there are only two basic steps involved: 1 . selection of dentine chroma in the cervical area, where enamel is the thinnest, using samples of the composite material; 2. selection of enamel tint, often performed by simple visual observation. In specific and less frequent cases, a third step might be involved in the form of a visual or photographic mapping of the tooth to identify special optical effects (such as white hypocalcifications, high chroma areas or localised opalescence zones). In this situation, the application of effect materials such as white, blue or orange-gold (ie Miris Effects, Coltenewhaledent) might be recommended.

\section{Layering technique and clinical application}

Composites can be applied following different incremental techniques for aesthetic or practical reasons as well as for better management of polymerisation stresses. ${ }^{19-20}$ The classical approach is the centrifugal technique, indicated for class III, small class IV and limited form corrections. It implies the placement in depth of one or two dentine layers (with an oblique position in large class III cavities) ${ }^{19}$ followed by the enamel layer, covering the entire surface. The other widely spread incremental approach is the bucco-lingual technique ${ }^{19-21}$ (Fig. 3). It makes use of a silicone key made from either a free-hand mock-up (simple cases) or wax-up (advanced cases). The first layer made of enamel, is then placed directly on the silicone index so that it provides in one single step the lingual profile, width and position of the incisal edge of the future restoration. Then, dentine and effect materials (when needed) can be applied in a precise 3-dimensional configuration; this provides the conditions for an optimal aesthetic result and, additionally, natural translucency, opalescence and halo effects.

\section{The effect of tooth ageing on dentine and enamel optical properties}

Special attention has to be paid to the morphological changes which affect the incisal edge structure due to tissue ageing and functional wear. Actually, in addition to the increase in dentine chroma and enamel translucency, the progressive thinning of the enamel layer and exposure of dentine at the incisal edge necessitates an adaptation of the layering technique (Fig. 3e). ${ }^{20}$

\section{Finishing \&t polishing technique}

Creating a correct shape and surface micro-morphology is the last critical step in restoring anterior teeth with free-hand bonding (Fig. 4). This procedure must follow a precise sequence, to allow an optimal result to be achieved predictably and rapidly (Fig. 4):

- proximal contours

- buccal and lingual profile

- transition lines

- incisal edge

- micromorphology.

These morphological elements are developed primarily with discs (ie Popon XT, 3M) while fine surface details are reproduced with fine diamonds (preferably flame shape, $40 \mu \mathrm{m}$ ) followed by silicone pre-polishers and finally silicone polishers (ie PoGo, Dentsply) or brushes (ie Occlusbrush, HaweNeos-Kerr or Diashine, Coltenewhaledent). When properly done, the quality and details of the surface provides a natural light reflection which warrants perfect aesthetic rendering.

\section{Longevity of direct composite restorations}

In contrary to the use of composite in posterior teeth which is very well documented over long periods of clinical service, ${ }^{2,3}$ there are only few data confirming the good behaviour of modern composites used in the smile frame. ${ }^{4}$ This might explain why porcelain veneers or bonded ceramic restorations are so often used in the same indication field with the idea that their bio-mechanical behaviour and aesthetic longevity would be more satisfactory than direct bonding. In fact, when analysing long-term clinical data regarding indirect veneers, a high survival rate was found (above 90\% at ten years ${ }^{22-23}$ with, however, the need of re-intervention in more than a third of restorations, ${ }^{22,24}$ The main reasons for failures were fractures of porcelain and marginal defects (from marginal discol-

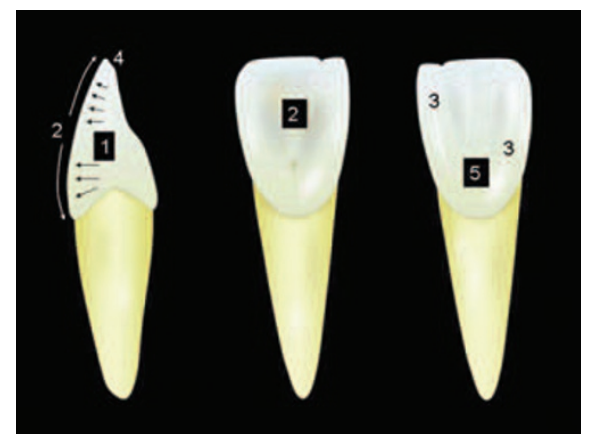

Fig. 4 Sequence of polishing providing optimal aesthetic outcome: 1 = proximal profile; 2 = buccal and lingual profiles; 3 = transition lines; 4 = incisal edge inclination; 5 = buccal micromorphology

ouration to recurrent decay). Predisposing factors for failures were found to be partial adhesion to dentine, presence of large composite restorations, endodontically treated teeth and heavy functional and parafunctional forces; those conditions interestingly can be also regarded as predisposing factors for failures in direct composite restorations. One can therefore conclude that in consideration of their long-term prognosis and aforementioned potential risks with indirect veneers, composite remains a material of choice for small decays or aesthetic enhancements, in particular when most of the buccal tooth surface remains intact.

\section{CONCLUSION}

Traditional restorative objectives have not changed over time; they were simply implemented by the aesthetic demands of an increasing number of patients. Composite resins then became the material of choice for young patients and less privileged people, or in case those which require a strictly conservative approach. The contemporary practitioner is ultimately challenged to replace the missing tissues or eventually modify their configuration by applying to the patientıs teeth an artificial material, which has to simulate the appearance of natural tissues.

The natural layering concept has enabled this objective to be achieved in a predictable way by incorporating newly acquired knowledge about natural tissue optical properties into contemporary composite systems. This advance can be regarded as a milestone in operative 
dentistry as it will give direct composite application a tremendous input, helping a larger number of our patients to receive more conservative and aesthetic restorations.

1. Osborne J W, Normann R D, Gale E N. A 12-year clinical evaluation of two composite resins. Quintessence Int 1990; 21: 111-114.

2. Hickel R, Manhart J. Longevity of restorations in posterior teeth and reasons for failure. J Adhes Dent 2001: 3: 45-64.

3. Manhart J, Chen H, Hamm G, Hickel R. Buonocore Memorial Lecture. Review of the clinical survival of direct and indirect restorations in posterior teeth of the permanent dentition. Oper Dent 2004; 29: 481-508.

4. Macedo G, Raj V, Ritter A V. Longevity of anterior composite restorations. J Esthet Restor Dent 2006; 18: 310-311.

5. Zachrisson B U, Mjör I A. Remodeling of teeth by grinding. Am J Orthod 1975; 68: 545-553.

6. Croll TP. Enamel microabrasion: observations after 10 years. J Am Dent Assoc 1997; 128: 45S-50S.

7. Heymann H O. Conservative concepts for achieving anterior esthetics. J Calif Dent Assoc 1997: 25: 437-443.

8. Leonard R H, Bentley C, Eagle J C, Garland G E et al. Nightguard vital bleaching: a long term study on the efficacy, shade retention, side effects and patient's perceptions. J Esthet Restor Dent 2001; 13: 257-369.

9. Ritter A V, Leonard R H, St-George A J, Caplan D J, Haywood V B. Safety and stability of nightguard vital bleaching: 9 to 12 years post-treatment. $J$ Esthet Restor Dent 2002; 14: 275-285.

10. Sundfeld R H, Croll T P, Briso A L, de Alexandre R $\mathrm{S}$, Sundfeld Neto D. Considerations about enamel microabrasion after 18 years. Am J Dent 2007; 20: 67-72.

11. Cook W D, McAree D C. Optical properties of esthetic restorative materials and natural dentition. J Biomed Mater Res 1985; 19: 469-488.

12. Dietschi $D, A r d u S, K$ Kejci I. Exploring the layering concepts for anterior teeth. In Roulet J F, Degrange $\mathrm{M}$ (eds). Adhesion - the silent revolution in dentistry. pp 235-251. Berlin: Quintessence Publishing, 2000.

13. Dietschi D, Ardu S, Krejci I. A new shading concept based on natural tooth color applied to direct composite restorations. Quintessence Int 2006; 37: 91-102.

14. Tuverson D. Orthodontic treatment using canines in place of missing lateral incisors: treatment planning considerations. Am J Orthod 1970 58: 109-127.

15. Nordquist G G, McNeill R W. Orthodontic vs. restorative treatment of the congenitally absent lateral incisor-long term periodontal and occlusal evaluation. J Periodontol 1975; 46: 139-143.

16. Dietschi D, Schatz J P. Current restorative modalities for young patients with missing anterior teeth. Quintessence Int 1997; 28: 231-240.

17. Freeman J E, Maskeroni A J, Lorton L. Frequency of Bolton tooth-size discrepancies among orthodontic patients. Am J Orthod Dentofacial Orthop 1996; 110: $24-27$

18. Ubassy G. Shape and color: the key to successful ceramic restorations. Berlin: Quintessenz Verlags, 1993.

19. Dietschi D. Free-hand composite resin restorations: a key to anterior aesthetics. Pract Periodontics Aesthet Dent 1995; 7: 15-25.

20. Dietschi D. Layering concepts in anterior composite restorations. J Adhes Dent 2001; 3: 71-80.

21. Dietschi D. Free-hand bonding in esthetic treatment of anterior teeth: creating the illusion. J Esthet Dent 1997; 9: 156-164.

22. Dumfahrt $H$, Schäffer $H$. Porcelain laminate veneers. A retrospective evaluation after 1 to 10 years of service: Part II--Clinical results. Int J Prosthodont 2000; 13: 9-18.

23. Layton D, Walton T. An up to 16 -year prospective study of 304 porcelain veneers. Int J Prosthodont 2007; 20: 389-396.

24. Peumans M, De Munck J, Fieuws S, Lambrechts $P$ et al. A prospective ten-year clinical trial of porcelain veneers. J Adhes Dent 2004; 6: 65-76. 